\title{
Photocatalytic Removal of Pharmaceuticals from Greywater
}

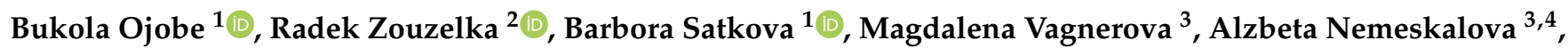 \\ Martin Kuchar $^{3}$ (D) Jan Bartacek ${ }^{1}$ and Jiri Rathousky ${ }^{2, *(D)}$
}

1 Department of Water Technology and Environmental Engineering, University of Chemistry and Technology Prague, Technicka 5, 16628 Prague, Czech Republic; bukola.ojobe@vscht.cz (B.O.); barbora.satkova@vscht.cz (B.S.); jan.bartacek@vscht.cz (J.B.)

2 Centre for Innovations in the Field of Nanomaterials and Nanotechnologies, J. Heyrovsky Institute of Physical Chemistry, Czech Academy of Sciences, Dolejskova 3, 18223 Prague, Czech Republic; radek.zouzelka@jh-inst.cas.cz

3 Forensic Laboratory of Biologically Active Substances, Department of Chemistry of Natural Compounds, University of Chemistry and Technology Prague, Technicka 5, 16628 Prague, Czech Republic; magdalena.vagnerova@vscht.cz (M.V.); alzbeta.nemeskalova@vscht.cz (A.N.); kuchara@vscht.cz (M.K.)

4 Department of Analytical Chemistry, University of Chemistry and Technology Prague, Technicka 5, 16628 Prague, Czech Republic

* Correspondence: jiri.rathousky@jh-inst.cas.cz

check for updates

Citation: Ojobe, B.; Zouzelka, R.; Satkova, B.; Vagnerova, M.; Nemeskalova, A.; Kuchar, M.; Bartacek, J.; Rathousky, J. Photocatalytic Removal of Pharmaceuticals from Greywater Catalysts 2021, 11, 1125. https:// doi.org/10.3390/catal11091125

Academic Editors: Jaime Carbajo and Patricia García-Muñoz

Received: 26 July 2021

Accepted: 16 September 2021

Published: 18 September 2021

Publisher's Note: MDPI stays neutral with regard to jurisdictional claims in published maps and institutional affiliations.

Copyright: (c) 2021 by the authors. Licensee MDPI, Basel, Switzerland. This article is an open access article distributed under the terms and conditions of the Creative Commons Attribution (CC BY) license (https:/ / creativecommons.org/licenses/by/ $4.0 /)$.

\begin{abstract}
High concentrations of pharmaceuticals have been detected in greywater effluents treated using up-to-date technologies. Finding a suitable additional treatment before this effluent is reused is urgently needed to ensure the reused water meets quality standards. This paper reports the use of heterogeneous photocatalysis on anatase and rutile nanopowders to remove naproxen, metformin and sulfamethoxazole, at practically relevant concentrations found in membrane bioreactor (MBR)treated greywater. A low anatase concentration of $400 \mathrm{mg} \mathrm{L}^{-1}$ was sufficient to efficiently degrade the pharmaceuticals listed above, with complete degradation observed in $5 \mathrm{~h}$. The effect of background species presented in greywater was, to some extent, comparable to that of the $\mathrm{OH}$-radical scavenger. These results prove that photocatalysis using anatase $\mathrm{TiO}_{2}$ is a feasible additional treatment for greywater recycling.
\end{abstract}

Keywords: greywater; photocatalysis; micropollutants; metformin; naproxen; sulfamethoxazole

\section{Introduction}

In recent years, the rapidly increased water scarcity index has emphasized the importance of recycling and reusing greywater, which can mitigate limited freshwater resources on activities where non-potable water could be utilized. Currently, the biggest obstacle in recycling greywater for irrigation, for instance, is the presence of micropollutants, specifically pharmaceuticals and personal care products [1-3]. Pharmaceuticals are bioactive, persistent and prone to bioaccumulation, posing a high risk when they enter the environment. Diclofenac, for instance, an analgesic, has been linked to the declined population of vultures in India, and carbamazepine, an antiepileptic, has detrimental effects on fish organs [4,5]. Unfortunately, most conventional treatment technologies used for greywater recycling have little or no capacity to remove pharmaceuticals due to various inhibitory factors.

Membrane bioreactors, which make use of the merging of biological degradation and filtration to recycle greywater, produce high-quality effluents. In most cases, regular pollutants (bacteria, inorganic and organic molecules) are entirely removed. However, such as other conventional technologies, this treatment method does not eliminate pharmaceuticals, such as Naproxen (NPX), Metformin (MTF) and Sulfamethoxazole (SMX), effectively. These pharmaceuticals, representing the different groups of Active Pharmaceutical Ingredients (APIs) with different structures and functional groups in play, have been found in 
concerning concentrations in raw and treated wastewater and even in greywater with low pollution indices. The reasons for this inadequate elimination are:

1. Their resistance to biodegradation;

2. Due to their small molecular sizes, the filtration modules are unable to create a suitable barrier to hold them back.

These sets of pharmaceuticals show various degrees of hydrophilicity with adsorption and biodegradation, a pathway for the elimination of hydrophobic and hydrophilic pharmaceuticals, respectively [6]. The fact is, when considering the effects of greywater reuse, the high removal efficiency of some of these pharmaceuticals is irrelevant due to their bioactive and bioaccumulatory abilities. Any seepage, even at low concentrations, is highly detrimental for reuse $[7,8]$.

To mitigate this situation, various tertiary treatment processes, i.e., additional steps after conventional wastewater treatment, have been used to significantly improve pharmaceuticals' removal. If applied successfully, they can expand the usability of greywater to more than mere flushing. Well-treated effluents can be used for unrestricted irrigation, car washing, fire dousing, laundry, etc. $[9,10]$. Of these treatment methods, Advanced Oxidation Processes (AOPs), which rely on the in situ production of reactive radical species able to degrade pharmaceuticals in wastewater [11], seem to be the most effective. Among these processes, heterogeneous photocatalysis can be used as a tool to purify pharmaceutically polluted wastewater [12-14].

$\mathrm{TiO}_{2}$ is the photocatalyst of choice, providing thermodynamically stable, non-toxic material with high photocatalytic activity. In combination with UV light, pharmaceuticals and their transformation products are degraded through a series of reactions [15]. Photocatalysis has proven to be a reliable course of treatment in removing pollutants from wastewater, leading to total degradation $[16,17]$. This performance is due to the formation of holes $\left(\mathrm{h}^{+}\right)$and reactive oxygen species, such as $\mathrm{OH}, \mathrm{O}_{2}{ }^{-}$, or $\mathrm{HO}_{2}$, on the photocatalyst surface $[18,19]$.

In recent times, pharmaceuticals, such as NPX, MTF and SMX, have been successfully degraded using $\mathrm{TiO}_{2}$ (often commercial Evonik P25 and, in rare cases, anatase $\mathrm{TiO}_{2}$ ) as a photocatalyst either in demineralized water solutions or in synthetic and real wastewaters [20-23]. NPX photocatalytic degradation was carried on different scales using its solutions in demineralized water, in river water and artificial wastewater [24-26]. However, the application of the $\mathrm{TiO}_{2}$ photocatalytic process in degrading NPX in real wastewater to study the effect of scavengers and other factors is very limited. The same holds for other two pharmaceuticals addressed in the present study, i.e., for MTF $[27,28]$ and SMX $[29,30]$.

The main research gap in this subject area is the absence of research extended to real greywater. What is especially missing is the understanding of the effects of different factors on the degradation of these three important pharmaceuticals. Generally, either anatase or anatase/rutile-mixed photocatalysts have been used. We also decided to add rutile, which, owing to different mechanistic pathways in comparison with anatase, may exhibit interesting performance features in the presence of potentially disturbing components in the water to be treated. The pharmaceuticals selected are among the most important present in real and MBR-treated greywater and photocatalysis was applied at environmentally relevant concentrations. Besides the photocatalysis itself, we also focus on other accompanying processes, namely, photolysis, adsorption on the photocatalyst surface and the natural scavenging species. In the long run, this enhanced treatment will help in expanding the usage of greywater and, in doing so, reduce the water scarcity index.

\section{Results}

\subsection{Photocatalysts Used and Their Characterization}

Table 1 summarizes the structure and texture characteristics of both $\mathrm{TiO}_{2}$ powders used. The phase content and the size of coherent regions were determined by the analysis of X-ray diffractograms, the broadening of the diffraction lines being interpreted only with 
regard to the crystal size and the microscopic deformations being neglected. The data showed that the anatase and rutile samples exclusively contained the relevant phase.

Table 1. Structure and texture characterization of photocatalysts used for the photocatalytic pharmaceuticals degradation.

\begin{tabular}{ccccccc}
\hline Photocatalyst & \multicolumn{2}{c}{$\begin{array}{c}\text { Phase Content } \mathbf{a} / \% \\
\text { Anatase Rutile }\end{array}$} & \multicolumn{2}{c}{$\begin{array}{c}\text { Crystallite Size a /nm } \\
\text { Anatase Rutile }\end{array}$} & Particle Size $\mathbf{b} / \mathbf{n m}$ & Particle Size $/ \mathbf{n m}$ \\
\hline A30 & 100 & 0 & 16 & - & 31 & $20-40$ \\
R30 & 0 & 100 & - & 29 & 100 & $30-100$ \\
\hline
\end{tabular}

${ }^{a}$ from X-ray diffractograms; ${ }^{b}$ from $\mathrm{N}_{2}$ sorption data; ${ }^{\mathrm{c}}$ from HR-TEM images.

Concerning the particle size, a comparative study using three physically different experimental techniques was carried out, including the X-ray diffraction, nitrogen sorption a HR-TEM microscopy. Surface areas calculated from sorption data using the BET method were converted to mean particle sizes using the spherical model approximation. A comparison of the particle size determined by the techniques mentioned enabled to draw some conclusions concerning the morphology properties of the powders.

Concerning the anatase sample A30, the size of the coherent region determined by X-ray diffraction was approximately half in comparison with the particle size determined by sorption and HR-TEM. Consequently, the extent of agglomeration of this material was limited to the formation of small clumps. Concerning the rutile sample R30, it consisted of crystals ca $30 \mathrm{~nm}$ in size which were aggregated to larger particles about three times greater as follows from the comparison of the XRD and sorption data.

\subsection{Photocatalytic Removal of Pharmaceuticals in Ultrapure Water and in the Presence of a Radical Scavenger}

\subsubsection{Naproxen}

The photocatalytic elimination of naproxen at an initial concentration of $2 \mathrm{mg} \mathrm{L}^{-1}$ was very effective (Figure 1). A low concentration of $400 \mathrm{mg} \mathrm{L}^{-1}$ of both allotropes was sufficient to achieve a very high degree of degradation, the complete removal of naproxen being attained within 40 and 180 min for A30 and R30, respectively.
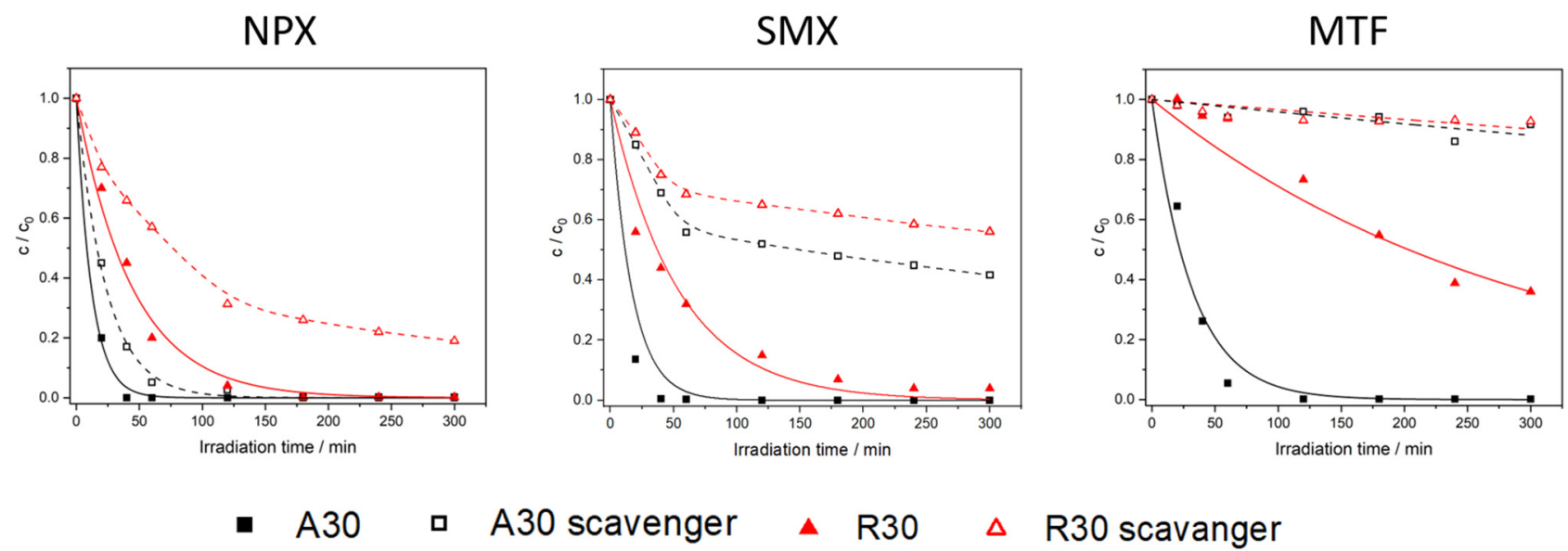

$\Delta$ R30 scavanger

Figure 1. The effect of radical scavenger added on the kinetics of the photocatalytic degradation of naproxen (NPX), sulfamethoxazole (SMX) and metformin (MTF) in the presence of anatase (A30) and rutile (R30).

The two accompanying processes, namely, photolysis and adsorption on the photocatalyst surface, were shown to play some role (Figure 2). Concerning photolysis, naproxen was partially degraded by UV-A irradiation $(20 \%)$ in the absence of the photocatalyst. This can be connected with the presence of the chromophores. Consequently, the degradation could only occur if the light fell within the absorption spectrum of naproxen. 


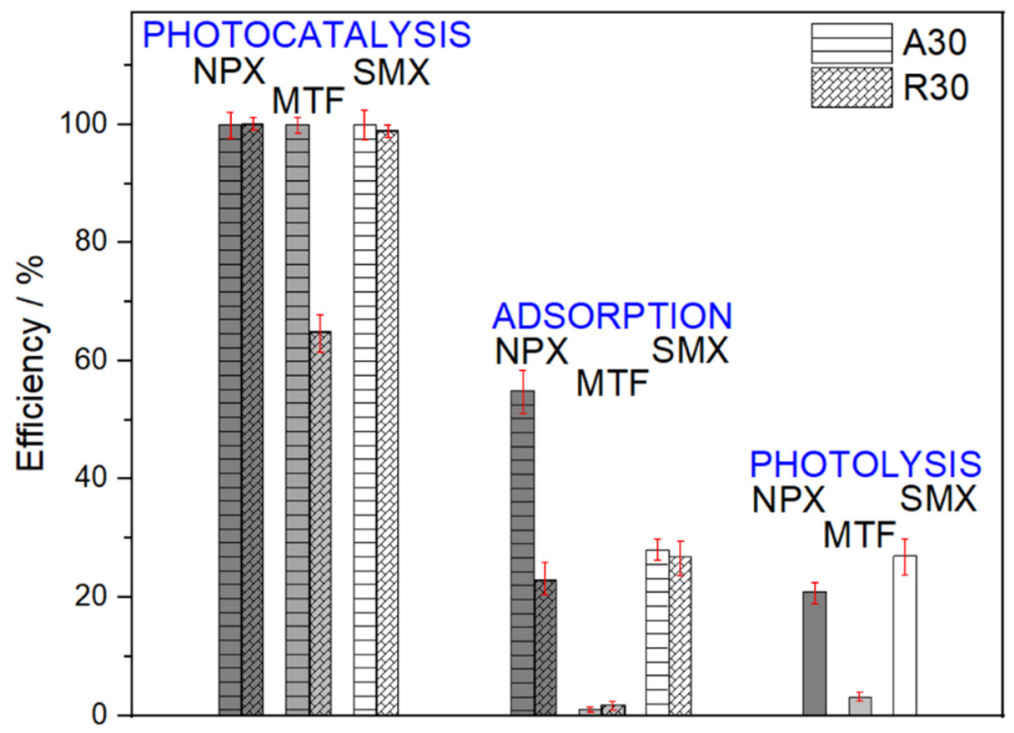

Figure 2. Comparison of the removal efficiencies of photocatalysis, adsorption and photolysis (all after $5 \mathrm{~h}$ ) for naproxen (NPX), sulfamethoxazole (SMX) and metformin (MTF).

The extent of adsorption on the surface of anatase A30 was significant. After $5 \mathrm{~h}$, when the equilibrium was achieved, the concentration of dissolved naproxen was halved. On rutile this effect was less pronounced, where the naproxen concentration decreased by about $20 \%$. The high sorption on anatase is important from the mechanistic point of view as photocatalytic mechanisms, including adsorbed species, can be expected to play a dominant role.

This conclusion was supported by the outcomes of the scavenger tests (Figure 3). The effect of the radical scavenger was relatively limited, the performance being to a large extent retained. This conclusion was valid especially for anatase A30, whose performance was only slightly affected by the presence of scavengers, complete degradation being achieved within $120 \mathrm{~min}$. For rutile, the performance was slightly worse; however, even here, a high degree of naproxen removal was attained.
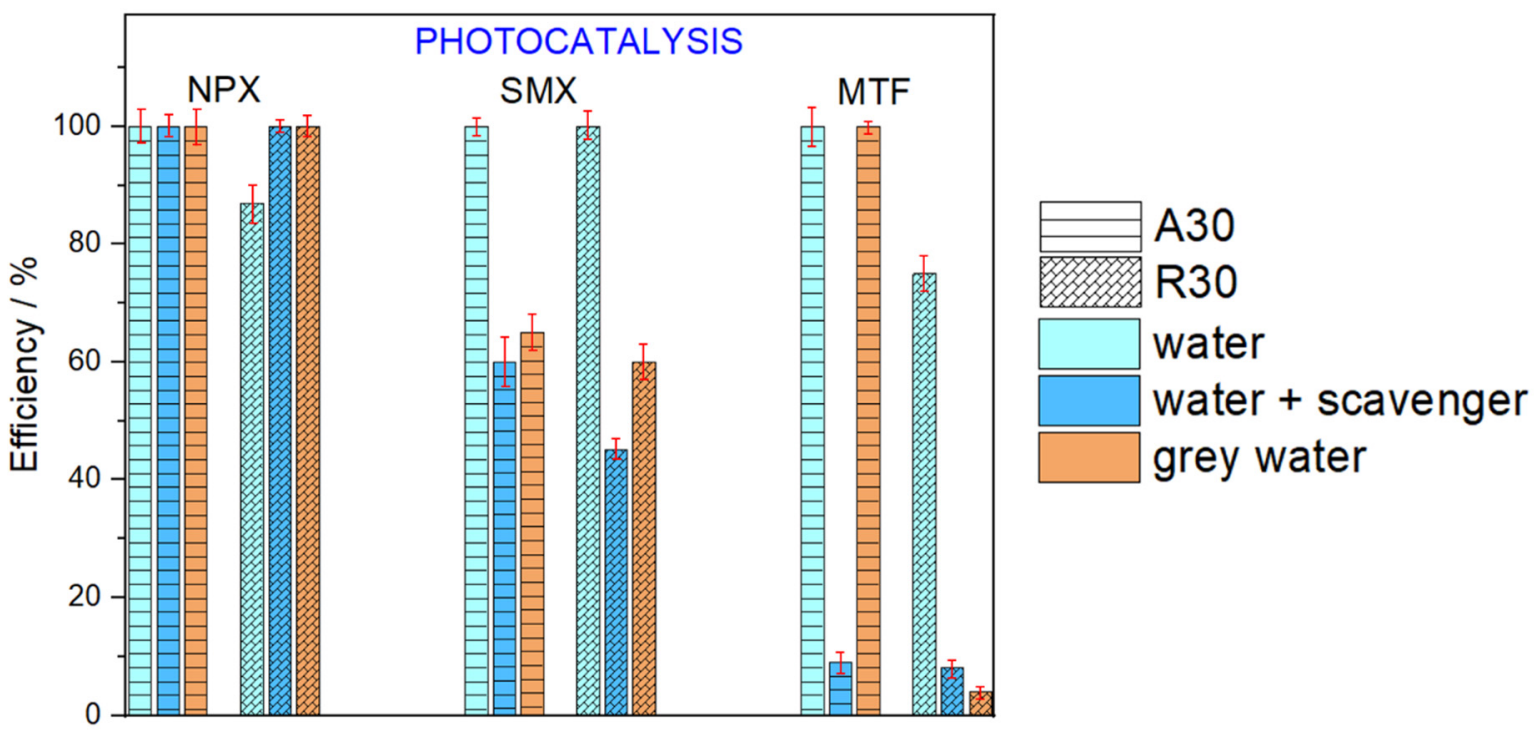

Figure 3. The comparison of the removal efficiencies of photocatalysis for naproxen (NPX), sulfamethoxazole (SMX) and metformin (MET) dissolved in ultrapure water, in ultrapure water with added scavenger and in grey water. The irradiation time equalled $5 \mathrm{~h}$. 


\subsubsection{Sulfamethoxazole}

Interesting was the comparison of data obtained for sulfamethoxazole with those for naproxen (Figure 1). The effect of photocatalysis in ultrapure water was comparable both on anatase and rutile. For anatase, the complete removal was achieved within $60 \mathrm{~min}$ for both pollutants.

Concerning the effect of photolysis and adsorption, both these processes play an important role (Figure 2). Adsorption on anatase was, approximately, in comparison with naproxen, while for rutile it was even higher. Additionally, the photolysis of sulfamethoxazole was relatively high, achieving about $25 \%$ after $5 \mathrm{~h}$, which was even more than that of naproxen.

The scavenger tests showed a substantial worsening of the performance, both for anatase and rutile (Figure 3). After $5 \mathrm{~h}$, the concentration of sulfamethoxazole for anatase and rutile decreased by only 50 and $40 \%$, respectively. As the effect of radical scavenger was much more pronounced in comparison with naproxen, a different degradation mechanism was to be expected. The role of radicals freed from the photocatalyst surface is clearly more important, which at least for anatase was in agreement with a lower adsorption in comparison with naproxen.

\subsubsection{Metformin}

The degradation of metformin on anatase in ultrapure water was only slightly slower than that for naproxen and sulfamethoxazole (Figure 1). The performance of rutile was substantially weaker, the decrease in the metformin concentration after $5 \mathrm{~h}$ achieving only about $65 \%$. What was, however, especially marked, was the devastating effect of the radical scavenger on the performance of both anatase and rutile. Therefore, a radical mechanism was to be expected for both photocatalysts [22]. This conclusion was in agreement with the adsorption experiments, which showed a practically negligible amount adsorbed. Additionally, the degree of photolysis was very small, which further supports the very low degradation efficiency in the presence of a radical scavenger. Additional kinetic curves are presented in the Supplementary Information (Figures S1 and S2).

\subsection{Photocatalytic Removal of Pharmaceuticals in MBR-Treated Greywater}

The MBR-treated greywater had a low pollutant load, and, hence, was of a high quality (Table 2). The degradation of naproxen and sulfamethoxazole in greywater followed a similar trend as their degradation in ultrapure water with the scavenger (Figure 3). For both water with the scavenger and greywater, complete removal was observed after $5 \mathrm{~h}$ of irradiation. Apparently, the significant adsorption of naproxen on the photocatalyst surface enables to preserve high performance, even in the presence of radical scavengers.

Table 2. Characteristics of MBR-treated greywater.

\begin{tabular}{lcc}
\hline & Parameter Range \\
\hline Dissolved oxygen $/ \mathrm{mg} \mathrm{L}^{-1}$ & & $6.7-8.5$ \\
Temperature $/{ }^{\circ} \mathrm{C}$ & & $22.6-26.0$ \\
Total nitrogen $/ \mathrm{mg} \mathrm{L}^{-1}$ & & $0.2-11.7$ \\
Total phosphorus $/ \mathrm{mg} \mathrm{L}^{-1}$ & & $0.1-0.4$ \\
Electric conductivity $/ \mathrm{MS} \mathrm{cm}^{-1}$ & & $412-500$ \\
$\mathrm{pH}$ & & $6.5-7.6$ \\
Dissolved organic carbon $/ \mathrm{mg} \mathrm{L}^{-1}$ & & $3.4-5.4$ \\
Solids $/ \mathrm{mg} \mathrm{L}^{-1}$ & Total suspended solids & Not detected \\
& Total dissolved solids & $310-358$ \\
\hline
\end{tabular}

As for sulfamethoxazole, a substantial decrease in the performance in comparison with ultrapure water was observed. The achieved efficiency, however, was slightly higher in comparison with the experiments with the ultrapure water containing scavenger. Therefore, it can be concluded that also for this pharmaceutical, the effect of background species 
contained in greywater on its photocatalytic degradation was similar to the role of the radical scavenger.

In the case of metformin, the results were contradictory. For rutile, the removal efficiency in greywater was very low, which corresponded to the effect of the radical scavenger (Figure 3). Surprisingly, in the case of anatase, high performance was observed with approx. $100 \%$ removal achieved in $5 \mathrm{~h}$, a similarity shared with naproxen.

\section{Discussion}

This paper showed the potential of $\mathrm{TiO}_{2}$ photocatalysis for the removal of pharmaceuticals with different chemical structures at practically relevant concentrations found in greywater influent.

\section{Degradation of Pharmaceuticals Using $\mathrm{TiO}_{2}$}

Slow, and for metformin practically negligible photolysis $(20 \%, 0 \%$ and $28 \%$ for naproxen, metformin and sulfamethoxazole, respectively, after $5 \mathrm{~h}$ ) clearly showed the degradation was mainly due to the photocatalytic process. The somehow higher degradation rate via photolysis of naproxen and sulfamethoxazole was believed to be due to photooxidation as oxygen was being mixed into the system by intensive stirring, in our case $400 \mathrm{rpm}$. Alternatively, the photolysis was carried out in the presence of inert $\mathrm{SiO}_{2}$ particles in suspension, whose particle size similar to those of anatase and rutile allotropes in order to exactly reproduce the light-scattering conditions. However, no difference in the comparison with experiments without particles was observed.

Further, the products of the photolytic and photocatalytic degradation may differ. Published studies show that for, e.g., naproxen, the degree of the degradation due to photocatalysis is much higher than due to photolysis (e.g., the application of only photolysis often leads to the formation of products which are of comparable or even higher toxicity than the untreated water). Therefore, the photocatalysis is a more suitable technology for the purification of water.

In most cases, the adsorption of pharmaceuticals on $\mathrm{TiO}_{2}$ is viewed as mostly negligible. However, our results showed that it can play an important role in the process of photocatalytic degradation. Especially for naproxen and sulfamethoxazole on the anatase surface, our adsorption experiments conducted separately in the dark demonstrated that adsorption can effectively remove, from the solution, the pharmaceuticals used in this study.

Naproxen was shown to be easily degraded using anatase. As the point of zero charge of $\mathrm{TiO}_{2}$ was around $\mathrm{pH} 5-6$, its surface was mostly not charged at neutral $\mathrm{pH}$ conditions used in our experiments and, also, valid for real greywater. The published studies suggest the carboxylic functional group of naproxen could be responsible for the efficient adsorption by strongly interacting with superficial $\mathrm{OH}$ groups leading to complexes. Owing to its large adsorption on the photocatalyst surface, the naproxen molecules can be easily degraded by the direct attack of holes.

This conclusion was supported by the scavenging tests, in which little effect on the degradation of naproxen was observed. In these tests, methanol basically functioned as a radical scavenger, even if some proportion of $\mathrm{CH}_{2} \mathrm{OH}$ radicals was formed before the formation of formaldehyde as a final product. Moreover, the adsorption of drugs on the surface could be different in the presence of methanol. Therefore, the $\mathrm{OH}$ radicals seemed to not play an important role. Finally, the preliminary TOC measurements showed that naproxen could be effectively mineralized in the range of $60-70 \%$.

The lower adsorption of sulphamethoxazole and of metformin could be due to the very different nature of the molecules with respect to the surface: highly hydrophobic to the drugs, hydrophilic to the surface. Similar to naproxen, sulfamethoxazole was also degraded at least to some extent in the adsorbed state.

Metformin was removed efficiently using anatase, although at a slower reaction rate in comparison with naproxen and sulfamethoxazole. Metformin can gain or lose a proton 
easily. As it has two distant $\mathrm{pK}_{\mathrm{a}}$ values equalling about 3 and about 13 (discussed in [28]), it can form a biprotonated form at a low $\mathrm{pH}$, the monoprotonated form at a medium $\mathrm{pH}$ between ca 3 and 13 and, finally, neutral species at the highest $\mathrm{pH}$. At the range of a $\mathrm{pH}$ typical for greywater, i.e., 6.5-7.6 (Table 2), metformin was mainly monoprotonated. Its high solubility in water $(1000 \mathrm{~g} / \mathrm{L})$ and its low $\mathrm{K}_{\mathrm{ow}}$ led to a practically negligible adsorption on the photocatalyst surface. Due to these features, the degradation mechanism of metformin by a direct attack of holes was less probable. Another issue was the formation of an intermediate product guanylurea, which is also recalcitrant. This leads to active competition for degradation between both species. Consequently, achieving a high degree of metformin degradation is much more difficult in comparison with the other two pharmaceuticals dealt with in this study.

In greywater, both allotropes of $\mathrm{TiO}_{2}$ were suitable to remove naproxen $\left(20 \mu \mathrm{g} \mathrm{L}^{-1}\right)$, reaching with anatase a $100 \%$ removal efficiency within less than $60 \mathrm{~min}$. For sulfamethoxazole, a similarity was found with the scavenger tests, showing that scavengers in the system slowed down degradation rates, but not enough to stop the reaction. If the experiment was left to run longer $(10 \mathrm{~h})$, the complete degradation of sulfamethoxazole was observed.

With metformin $\left(300 \mu \mathrm{g} \mathrm{L}^{-1}\right)$ in greywater, a surprisingly high efficiency was observed using anatase as the photocatalyst, which was very beneficial from the point of view of the application. This phenomenon could be explained as follows: Dissolved organic matter present in greywater (Table 2) is known to have a higher adsorption affinity onto the $\mathrm{TiO}_{2}$ surface in comparison with alcohols used as radical scavenges [29]. However, as the adsorption of metformin on the $\mathrm{TiO}_{2}$ surface is very low, the effect of the preferential adsorption of dissolved organic matter should be negligible, as there is no competition between them. For methanol used as a radical scavenger, a dramatic effect was observed as it efficiently destroyed the $\mathrm{OH}$ radicals, which were decisive in the degradation of metformin. Consequently, the effect of these two components, i.e., methanol and dissolved organic matter, was not comparable, which differentiated this pharmaceutical from the other two included in this study.

The very low efficiency of rutile in greywater was in an agreement with the data obtained using a radical scavenger. The practical inability of rutile to degrade metformin in greywater could be due to a number of reasons. The increased ionic strengths expected due to a slightly higher dissolved salt content compared to drinking water can be such a reason why metformin molecules have limited migration power to the rutile surface (this is the primary means of degradation using rutile $\mathrm{TiO}_{2}$ ) [30], or there was also a competition between scavengers (methanol or dissolved organic matter) and metformin with scavengers being more mobile, which would be degraded first. Finally, the UV lightinduced aggregation of $\mathrm{TiO}_{2}$ particles, which was much stronger for rutile, might have been the reason of the worse performance of rutile than anatase [31].

\section{Materials and Methods}

\subsection{Pharmaceuticals}

Metformin hydrochloride, naproxen and sulfamethoxazole (Figure 4) were purchased from Sigma-Aldrich, Taufkirchen, Germany, titanium dioxide nanopowders from U.S. Research Nanomaterials, Houston, TX, USA, methanol and sodium hydroxide from Penta, Czech Republic. Ultrapure water was used for all experiments as a matrix, its purity being tested before each experiment. All apparatuses were washed with distilled water and methanol according to a standard procedure to remove impurities that could contaminate the experiments.

For these experiments, $2 \mathrm{mg} \mathrm{L}^{-1}$ of each pharmaceutical was dissolved in water. While metformin hydrochloride and naproxen could be dissolved directly, sulfamethoxazole, which is practically insoluble in water, was alkalified using $0.1 \mathrm{M}$ sodium hydroxide to increase the solution's $\mathrm{pH}$; thus, increasing solubility. 
<smiles>COc1ccc2cc([C@@H](C)C(=O)O)ccc2c1</smiles>

(a)

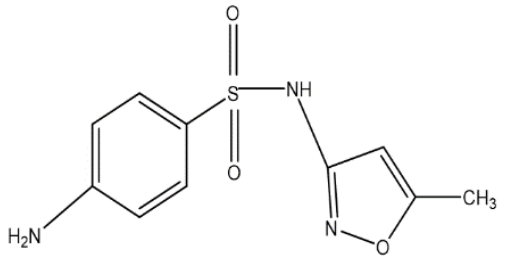

(b)<smiles>CN(C)C(=N)NC(=N)N</smiles>

(c)

Figure 4. Structural structure of Naproxen (a), sulfamethoxazole (b) and metformin (c).

\section{2. $\mathrm{TiO}_{2}$ Photocatalysts}

$\mathrm{TiO}_{2}$ nanopowders ( $\geq 99.5 \%$ purity) included two pristine allotropic forms of $\mathrm{TiO}_{2}$, namely, rutile and anatase, their nominal particle size according to the producer being $30 \mathrm{~nm}$. Structural and textural properties of the nanoparticles were determined by combining several techniques. Surface morphology was followed with scanning electron microscopy (SEM, JEOL JSM 5500LV) combined with high-resolution transmission electron microscopy (HR-TEM, JEOL JEM-2100Plus). Crystallinity (structure and phase composition) of the titania dioxide samples was evaluated by powder X-ray diffraction (pXRD) using PANalytical X'Pert PRO diffractometer equipped with Co anode in the Bragg-Brentano geometry and multichannel $X^{\prime}$ Celerator detector. The surface area of powders was determined from nitrogen sorption isotherms at ca $77 \mathrm{~K}$ (boiling point of liquid nitrogen) using a Micromeritics 3Flex apparatus. Prior to the measurements, the samples were degassed at $250{ }^{\circ} \mathrm{C}$ overnight.

\subsection{Photocatalytic Experiments}

Before the photocatalytic experiments, the photocatalyst samples were cleaned overnight by UV light of a dominant wavelength of $365 \mathrm{~nm}$ with an irradiation intensity of $2.0 \mathrm{~mW} \mathrm{~cm} \mathrm{~cm}^{-2}$ to decompose any residual organic matter on them. The pharmaceuticals in aqueous solution $\left(2 \mathrm{mg} \mathrm{L}^{-1}\right)$ were photocatalytically degraded at $25^{\circ} \mathrm{C}$ using photocatalyst dispersion ( $400 \mathrm{mg} \mathrm{L}^{-1}$ ) in a $25 \mathrm{~mL}$ quartz cell (Figure 5). As the top of the liquid in the cell was open to air and the solution was intensively stirred (400 rpm), the concentration of dissolved oxygen was constant during the experiment. A Sylvania Lynx-S 11 W BLB lamp irradiated the aqueous dispersion with UV light $(365 \mathrm{~nm})$ at a low-power density of $1.0 \mathrm{~mW} \mathrm{~cm}{ }^{-2}$. Prior to the photocatalytic experiments, the dissolved pharmaceuticals were equilibrated with the photocatalyst surface for $3 \mathrm{~h}$. For each experiment, aliquots each of $100 \mu \mathrm{L}$ were collected from the solution in the reaction cell every $20 \mathrm{~min}$ for the first one hour and once every hour for the next $4 \mathrm{~h}$. The samples were filtered immediately after collection to stop the reaction process from continuing, stored in amber vials to limit light interaction with the analytes, and frozen at $-20^{\circ} \mathrm{C}$, to keep the samples from degrading. The samples were defrosted just before they were subjected to HPLC-MS analysis. The pseudo first-order reaction rate constants for the degradation of pharmaceuticals were calculated using nonlinear regression fitting of the kinetic curves. 


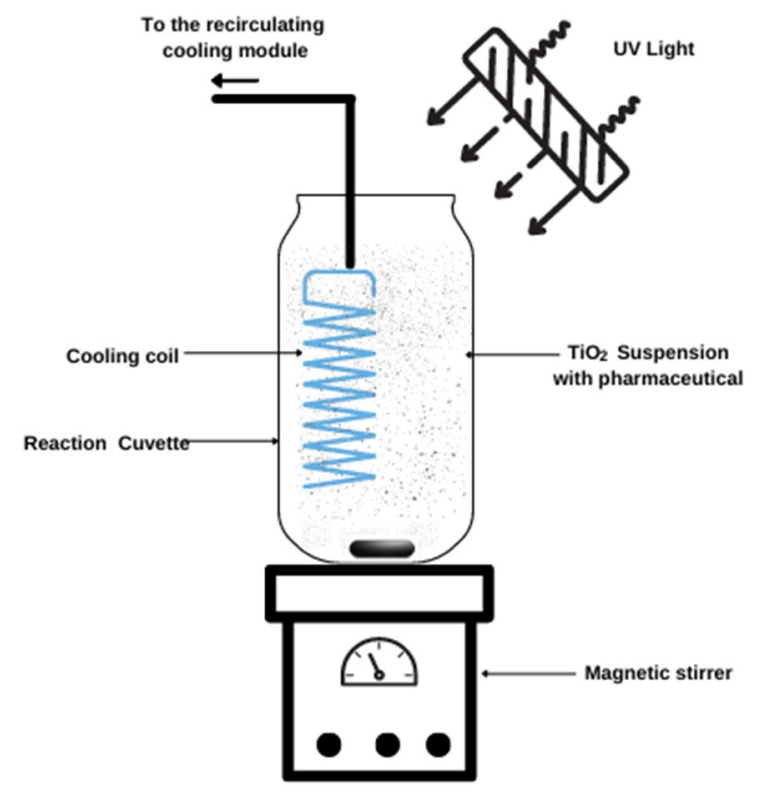

Figure 5. Photocatalytic module for the degradation of pharmaceutical dissolved in greywater.

\subsection{Adsorption, Photolysis and Scavenger Experiments}

To determine the effect of adsorption on the surface of $\mathrm{TiO}_{2}$ nanoparticles, experiments analogous to the photocatalytic ones were conducted in the dark with the same stirring speed and sampling performed at 0,3 and $5 \mathrm{~h}$.

The photostability of the pharmaceuticals was tested by subjecting their solutions to UV light without the photocatalysts for $5 \mathrm{~h}$, sampling being conducted at 0,3 and $5 \mathrm{~h}$.

A solution of $0.1 \mathrm{M}$ methanol was used as a $\mathrm{OH}$ radical scavenger, the sampling during the photocatalytic experiments being carried out once every hour as slow degradation rates were expected. The samples obtained were treated analogously to those collected during the photocatalytic degradation experiments.

\subsection{Lab-Scale MBR Treatment of Greywater}

Greywater from an apartment building with 99 flats and approx. 300 inhabitants was collected periodically and treated in a 3 L MBR reactor fitted with two ultrafiltration hollow tube membranes running in series. This lab-sized reactor was run for a year and high-quality effluent was produced throughout the operation of the reactor (Table 2). The hydraulic retention time of the reactor was approx. $24 \mathrm{~h}$ at the time of sample collection. HPLC analyses were carried out on raw greywater samples collected and the highest concentrations analysed for naproxen, metformin and sulfamethoxazole were 20,300 and $50 \mu \mathrm{g} \mathrm{L}^{-1}$, respectively.

\subsection{Analytical Methods}

The separation of analytes was carried out using HPLC (Agilent Infinity 1290 HPLC, Agilent Technologies, Santa Clara, CA, USA) equipped with a Poroshell 120 EC-C18 $(100 \mathrm{~mm} \times 2.1 \mathrm{~mm}, 2.7 \mu \mathrm{m}$ particle size) column with a guard column (both by Agilent Technologies, Santa Clara, CA, USA). The column temperature was set at $40^{\circ} \mathrm{C}$, and the injection volume was $1 \mu \mathrm{L}$. The mobile phases consisted of $0.5 \mathrm{mM}$ ammonium fluoride in water (solvent A) and methanol (solvent B). The flow rate was $0.4 \mathrm{~mL} / \mathrm{min}$. The mobile phase composition started at $20 \%$ B and was linearly increased to $100 \%$ B in $5 \mathrm{~min}$. After each run, the column was re-equilibrated for $1 \mathrm{~min}$. The $6460 \mathrm{QqQ}$ Triple Quad mass spectrometer (Agilent Technologies, Santa Clara, CA, USA) equipped with Agilent Jet Stream technology in positive electrospray (ESI+) ionization mode was used for the analyte detection. The quantitative analysis was performed using dynamic Multiple Reaction Monitoring (dMRM). The following MRM transitions were monitored: metformin $-130 \rightarrow 85,71$; 
naproxen $-231 \rightarrow 170,153,141$; sulphamethoxazole $-254 \rightarrow 155.8,107.9,92$. The capillary voltage was set at $3500 \mathrm{~V}$. The sheath gas flow and temperature were set at $11.0 \mathrm{~L} \mathrm{~min}^{-1}$ and $250{ }^{\circ} \mathrm{C}$, respectively. The drying gas flow and temperature were set at $5 \mathrm{~L} \mathrm{~min}^{-1}$ and $300{ }^{\circ} \mathrm{C}$, respectively. The nebulizer pressure was 45 psi. The quantification was performed using external calibration. Agilent Mass Hunter software was used for data collection and processing.

\section{Conclusions}

We demonstrated the high efficiency of anatase $\mathrm{TiO}_{2}$ in degrading photocatalytically naproxen, metformin and sulfamethoxazole in greywater. Even if their chemical compositions and physico-chemical properties substantially differ, a high degree of their removal by photocatalysis in greywater was achieved. Despite the vastly differing sorption properties of individual pharmaceuticals on the photocatalyst surface, this property did not constitute a critical parameter in the degradation process. This observation has a major importance in a real application of the photocatalytic technology in greywater treatment, as the content of the background components may be vastly varied.

As our results showed a high potential of the photocatalysis application, further work will be focused on more recalcitrant pharmaceuticals, which may be contained in other real greywater samples, and on immobilised forms of $\mathrm{TiO}_{2}$. Immobilized $\mathrm{TiO}_{2}$ opens a new way for the implementation of photocatalytic technology in continuous water treatment set-ups.

Supplementary Materials: The following are available online at https: / www.mdpi.com/article / 10.3390/catal11091125/s1, Figure S1: Kinetics of photocatalytic degradation of metformin (MTF), naproxene (NPX) and sulfomethaxazole (SMX) carried out in the suspension of anatase and rutile $30 \mathrm{~nm}$ nanoparticles; Figure S2: UV-A photolysis of metformin (MTF), naproxene (NPX) and sulfomethaxazole (SMX).

Author Contributions: Conceptualization, J.R. and J.B.; methodology, J.R. and R.Z.; validation, B.O., M.V. and A.N.; investigation, B.O., B.S., M.V., A.N. and M.K.; data curation, B.O., J.R., M.V., A.N. and R.Z.; writing—original draft preparation, B.O.; writing—review and editing, J.R., R.Z. and J.B.; supervision, J.R., M.K. and J.B.; project administration, J.R. and J.B.; funding acquisition, J.R. and J.B. All authors have read and agreed to the published version of the manuscript.

Funding: This research was funded by the Czech Science Foundation (GACR, grant no. 19-21801S) and the Technology Agency of the Czech Republic (TACR, grant no. TH03030408).

Institutional Review Board Statement: Not applicable.

Informed Consent Statement: Not applicable.

Data Availability Statement: Not applicable.

Acknowledgments: This work was also supported by the Ministry of Education, Youth and Sports of the Czech Republic and The European Union-European Structural and Investments Funds in the frame of Operational Programme Research, Development and Education-project Pro-NanoEnviCz (project no. CZ.02.1.01/0.0/0.0/16_013/0001821), which provided access to a Micromeritics 3Flex apparatus, Nicolet FTIR 6700 spectrophotometer and Beckman Coulter Optima XPN-100 ultracentrifuge. Further, we thank the University of Chemistry and Technology, Prague for the financial support from specific university research (MSMT no 21-SVV /2019), the Academy of Sciences of the Czech Republic for the financial support (projects no. MSM200402101 and Strategy AV21, 16/2021) and Ministry of Education, Youth and Sports of the Czech Republic (Barrande programme no. 8J20FR012).

Conflicts of Interest: The authors declare no conflict of interest.

\section{References}

1. Zhang, T.; Li, B. Occurrence, transformation, and fate of antibiotics in municipal wastewater treatment plants. Crit. Rev. Environ. Sci. Technol. 2011, 41, 951-998. [CrossRef]

2. Benotti, M.J.; Trenholm, R.A.; Vanderford, B.J.; Holady, J.C.; Stanford, B.D.; Snyder, S. Pharmaceuticals and endocrine disrupting compounds in U.S. drinking water. Environ. Sci. Technol. 2008, 43, 597-603. [CrossRef] 
3. Luo, Y.; Guo, W.; Ngo, H.H.; Nghiem, L.D.; Hai, F.; Zhang, J.; Liang, S.; Wang, X. A review on the occurrence of micropollutants in the aquatic environment and their fate and removal during wastewater treatment. Sci. Total Environ. 2014, 473-474, 619-641. [CrossRef]

4. Green, R.E.; Newton, I.; Shultz, S.; Cunningham, A.A.; Gilbert, M.; Pain, D.J.; Prakash, V. Diclofenac poisoning as a cause of vulture population declines across the Indian subcontinent. J. Appl. Ecol. 2004, 41, 793-800. [CrossRef]

5. Weber, F.-A.; der Beek, T.A.; Carius, A.; Grüttner, G.; Hickmann, S.; Ebert, I.; Hein, A.; Küster, A.; Rose, J.; Koch-Jugl, J. Pharmaceuticals in the Environment-The Global Perspective Occurrence, Effects, and Potential Cooperative Action under SAICM; German Environment Agency: Dessau-Roßlau, Germany, 2014.

6. Bolong, N.; Ismail, A.; Salim, M.R.; Matsuura, T. A review of the effects of emerging contaminants in wastewater and options for their removal. Desalination 2009, 239, 229-246. [CrossRef]

7. Boyjoo, Y.; Pareek, V.K.; Ang, M. A review of greywater characteristics and treatment processes. Water Sci. Technol. 2013, 67, 1403-1424. [CrossRef] [PubMed]

8. Liu, S.; Butler, D.; Memon, F.; Makropoulos, C.; Avery, L.; Jefferson, B. Impacts of residence time during storage on potential of water saving for grey water recycling system. Water Res. 2010, 44, 267-277. [CrossRef] [PubMed]

9. Etchepare, R.; van der Hoek, J.P. Health risk assessment of organic micropollutants in greywater for potable reuse. Water Res. 2015, 72, 186-198. [CrossRef]

10. Van Der Hoek, J.P.; Tenorio, J.L.I.; Hellinga, C.; Van Lier, J.B.; Van Wijk, A.J.M. Green village delft-Integration of an autarkic water supply in a local sustainable energy system. J. Water Reuse Desalination 2014, 4, 154-163. [CrossRef]

11. Butkovskyi, A.; Sevenou, L.; Meulepas, R.J.W.; Leal, L.H.; Zeeman, G.; Rijnaarts, H.H.M. Micropollutant removal from black water and grey water sludge in a UASB-GAC reactor. Water Sci. Technol. 2017, 77, 1137-1148. [CrossRef]

12. Govindan, K.; Angelin, A.; Kalpana, M.; Rangarajan, M.; Shankar, P.; Jang, A. Electrocoagulants characteristics and application of electrocoagulation for micropollutant removal and transformation mechanism. ACS Appl. Mater. Interfaces 2019, 12, 1775-1788. [CrossRef] [PubMed]

13. Maher, E.K.; O’Malley, K.N.; Dollhopf, M.E.; Mayer, B.K.; McNamara, P.J. Removal of estrogenic compounds from water via energy efficient sequential electrocoagulation-electrooxidation. Environ. Eng. Sci. 2020, 37, 99-108. [CrossRef]

14. Lee, C.M.; Palaniandy, P.; Dahlan, I. Pharmaceutical residues in aquatic environment and water remediation by TiO ${ }_{2}$ heterogeneous photocatalysis: A review. Environ. Earth Sci. 2017, 76, 611. [CrossRef]

15. Foteinis, S.; Borthwick, A.G.; Frontistis, Z.; Mantzavinos, D.; Chatzisymeon, E. Environmental sustainability of light-driven processes for wastewater treatment applications. J. Clean. Prod. 2018, 182, 8-15. [CrossRef]

16. Gimeno, O.; García-Araya, J.; Beltrán, F.; Rivas, F.; Espejo, A. Removal of emerging contaminants from a primary effluent of municipal wastewater by means of sequential biological degradation-solar photocatalytic oxidation processes. Chem. Eng. J. 2016, 290, 12-20. [CrossRef]

17. Gassie, L.W.; Englehardt, J.D. Advanced oxidation and disinfection processes for onsite net-zero greywater reuse: A review. Water Res. 2017, 125, 384-399. [CrossRef]

18. Miranda-García, N.; Suárez, S.; Sanchez, B.; Coronado, J.; Malato, S.; Maldonado, M.I. Photocatalytic degradation of emerging contaminants in municipal wastewater treatment plant effluents using immobilized $\mathrm{TiO}_{2}$ in a solar pilot plant. Appl. Catal. $B$ Environ. 2011, 103, 294-301. [CrossRef]

19. Pirilä, M.; Saouabe, M.; Ojala, S.; Rathnayake, B.; Drault, F.; Valtanen, A.; Huuhtanen, M.; Brahmi, R.; Keiski, R.L. Photocatalytic degradation of organic pollutants in wastewater. Top. Catal. 2015, 58, 1085-1099. [CrossRef]

20. Du Pisani, P.L. Direct reclamation of potable water at Windhoek's Goreangab reclamation plant. Desalination 2006, 188, 79-88. [CrossRef]

21. Chen, X.; Richard, J.; Liu, Y.; Dopp, E.; Tuerk, J.; Bester, K. Ozonation products of triclosan in advanced wastewater treatment. Water Res. 2012, 46, 2247-2256. [CrossRef]

22. Prashanth, V.; Priyanka, K.; Remya, N. Solar photocatalytic degradation of metformin by $\mathrm{TiO}_{2}$ synthesized using Calotropis gigantea leaf extract. Water Sci. Technol. 2021, 83, 1072-1084. [CrossRef]

23. Jallouli, N.; Elghniji, K.; Hentati, O.; Ribeiro, A.R.; Silva, A.; Ksibi, M. UV and solar photo-degradation of naproxen: TiO 2 catalyst effect, reaction kinetics, products identification and toxicity assessment. J. Hazard. Mater. 2016, 304, 329-336. [CrossRef] [PubMed]

24. Kanakaraju, D.; Motti, C.; Glass, B.D.; Oelgemöller, M. Solar photolysis versus $\mathrm{TiO}_{2}$-mediated solar photocatalysis: A kinetic study of the degradation of naproxen and diclofenac in various water matrices. Environ. Sci. Pollut. Res. 2016, 23, 17437-17448. [CrossRef] [PubMed]

25. Roncaroli, F.; Blesa, M.A. Kinetics of adsorption of carboxylic acids onto titanium dioxide. Phys. Chem. Chem. Phys. 2010, 12, 9938-9944. [CrossRef] [PubMed]

26. Dobson, K.D.; McQuillan, A. In situ infrared spectroscopic analysis of the adsorption of aliphatic carboxylic acids to $\mathrm{TiO}_{2}, \mathrm{ZrO}_{2}$, $\mathrm{Al}_{2} \mathrm{O}_{3}$, and $\mathrm{Ta}_{2} \mathrm{O}_{5}$ from aqueous solutions. Spectrochim. Acta Part A Mol. Biomol. Spectrosc. 1999, 55, 1395-1405. [CrossRef]

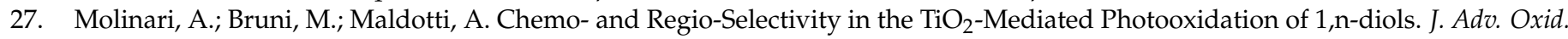
Technol. 2008, 11, 143-148. [CrossRef]

28. Hernández, B.; Pflüger, F.; Kruglik, S.G.; Cohen, R.; Ghomi, M. Protonation-deprotonation and structural dynamics of antidiabetic drug metformin. J. Pharm. Biomed. Anal. 2015, 114, 42-48. [CrossRef] 
29. Brame, J.; Long, M.; Li, Q.; Alvarez, P. Inhibitory effect of natural organic matter or other background constituents on photocatalytic advanced oxidation processes: Mechanistic model development and validation. Water Res. 2015, 84, 362-371. [CrossRef]

30. Samayamanthula, D.R.; Sabarathinam, C.; Bhandary, H. Treatment and effective utilization of greywater. Appl. Water Sci. 2019, 9, 90. [CrossRef]

31. Zhou, C.; Bashirzadeh, Y.; Bernadowski, T.A.; Zhang, X. UV Light-Induced Aggregation of Titania Submicron Particles. Micromachines 2016, 7, 203. [CrossRef] 